\title{
Myelination Determines the Caliber of Dorsal Root Ganglion Neurons in Culture ${ }^{1}$
}

\author{
ANTHONY J. WINDEBANK, ${ }^{2}$ PATRICK WOOD, RICHARD P. BUNGE, AND PETER JAMES DYCK \\ Mayo Clinic, Rochester, Minnesota 55905, and Washington University School of Medicine, St. Louis, Missouri 63110
}

\begin{abstract}
In order to understand the relationship of supporting cells to the differentiation of neurons in culture, we have used morphometry to study myelination of dorsal root ganglion (DRG) neurons by central or peripheral supporting cells. Dissociated DRG cultures from 15-day rat embryos, free of Schwann cells and fibroblasts, were prepared, and supporting cells were added from spinal cord or DRG; myelination commenced after 2 weeks. Control cultures received no supporting cells. At 7,14 , and 24 days, a total of 22 cultures were processed for electron microscopy. Three fascicles from defined points were sampled from each culture. In cultures containing glial cells, smaller fibers $(p<0.001)$ were myelinated (mean of median diameter, $1.13 \pm 0.13$ (SD) $\mu \mathrm{m}$ ) than in cultures containing Schwann cells $(1.67 \pm 0.17 \mu \mathrm{m})$, although there was no difference $(p>0.1)$ in the degree of myelination expressed as number of myelin lamellae/fiber. A new finding concerned the relationship of axonal diameter to the presence or absence of myelinating cells. In control cultures without supporting cells or in areas where supporting cells were absent, the range of neurite diameter $(0.05$ to 1.25 $\mu \mathrm{m}$ ) and the median diameter (mean of median, $0.24 \pm 0.03$ $\mu \mathrm{m})$ were similar at different times $(7,14$, and 24 days), demonstrating a stable population of neurite diameters throughout the period. In myelinated fascicles, a different distribution of neurite diameters was present. Myelinated neurites had a greater median diameter (measured to inner border of myelin) and a different range of fiber diameters compared to bare neurites. For Schwann cells, this range was 0.7 to $3.4 \mu \mathrm{m}$, and the mean of median diameters was $1.67 \pm 0.17 \mu \mathrm{m}$; for glial cells, the range was 0.6 to $2.4 \mu \mathrm{m}$, and the mean of median diameters $1.13 \pm 0.13 \mu \mathrm{m}$. Differences between myelinated and bare fibers were all highly significant $(p<0.001)$. The absence of the larger-diameter peak in fascicles containing only bare neurites suggests that myelination by Schwann cells or oligodendrocytes is necessary for the expression of axonal diameter greater than 1.25 $\mu \mathrm{m}$ in this tissue culture system.
\end{abstract}

Interaction between the axon and glial cell in the process of myelination represents one of the most highly differentiated cell-to-

Received July 5, 1984; Revised November 2, 1984;

Accepted November 8, 1984

\footnotetext{
${ }^{1}$ This investigation was supported by a Teacher Investigator Award (NS00681) from the National institute of Neurological and Communicative Disorders and Stroke (A. J. W.), by funds from the National Multiple Sclerosis Society (P. W. and R. P. B.), and by Mayo and Mooney Funds.

${ }^{2}$ To whom correspondence should be addressed.
}

cell contact models. Much emphasis has, therefore, been placed on the axonal factors responsible for inducing cell division and myelin membrane formation, while relatively little attention has been directed toward the reverse interaction; that is the role that glial cells have in influencing axonal development or behavior. Reproducible myelin formation in the absence of axons or neurites has not been demonstrated. A single early report described myelin formation by Schwann cells in association with glass and nylon fibers (Ernyei and Young, 1966); this has not been reproduced. A more recent study suggested that oligodendrocytes may elaborate small amounts of myelin membrane in the absence of neurons (Bradel and Prince, 1983). There are also indications that very small quantities of myelin precursors are formed in the down-regulated. nonmyelinating Schwann cell (Poduslo et al., 1984). It has been demonstrated that neuronal membranes are mitogenic for Schwann cells (Salzer et al., 1980a; DeVries et al., 1982) and that this mitogenesis requires membrane contact (Salzer et al., 1980b).

Using quantitative morphological techniques, this study addresses the role that Schwann cells and central glial cells have in determining axonal characteristics in the rat dorsal root ganglion tissue culture system. The results demonstrate a critical influence of non-neuronal cells on the expression of axonal diameter

\section{Materials and Methods}

Using previously established methods (Wood, 1976; Wood et al., 1980), three different types of culture system were used, and cells derived from each were combined in various ways to provide the desired end results.

Dorsal root ganglion neurons. Dorsal root ganglia were dissected out of 15-day rat embryos, pretreated with trypsin, and triturated to provide a suspension of dorsal root ganglion cells in medium supplemented with $10 \%$ human placental serum (HPS) and nerve growth factor (NGF). This suspension was plated out onto a collagen substrate in a flexible molded plastic dish. After cells had settled, they were incubated for 12 days in a medium containing $10^{-6} \mathrm{M}$ fluorodeoxyuridine and $10 \% \mathrm{HPS}$. During this period, neurite outgrowth occurs and interconnects the neuronal soma, while mitotic supporting cells (Schwann cells and fibroblasts) are eliminated. Twenty-four neuronal networks were established, and populations of supporting cells were added as described below.

Schwann cells. Schwann cell donor explants were prepared from the dorsal root ganglia of 16-day embryo rats. After dissection, the ganglia were placed on a collagen substrate and incubated in a medium containing $10^{-6}$ $M$ fluorodeoxyuridine and $10 \%$ HPS for 8 days. During this period, neurite outgrowth appeared without supporting cells. However, when such ganglia are reexplanted into a new medium without antimetabolites, there is a rapid outgrowth of neurites and supporting Schwann cells but relatively few fibroblasts.

Central glial cells. The spinal cord was dissected from 14-day rat embryos. The isolated cord was split along the dorsal sulcus, and the alar portion of the cord was removed to the level of the sulcus limitans. The remaining basal part of the cord was then cut into pieces of size equivalent to the dorsal root ganglion fragments described above. These fragments contain ventral root and other neurons, oligodendroglia, astrocytes, and vascular elements.

Cellular combinations. After the pretreatment described, cell types were combined in the following ways to provide three different model systems:

Series 1 . Spinal cord fragments ( 4 per network) placed on the neurite and 
neuronal network from the dorsal root ganglia. Glial cells migrated into the area surrounding the explanted cord fragment. The remainder of the network remained unpopulated by supporting cells.

Series 2. Dorsal root ganglia fragments (4 per network) placed on the neurite and neuronal network from the dorsal root ganglia. This provided the same type of network as above, populated and myelinated by Schwann cells derived from the dorsal root ganglia. Again, the network was only populated in the area surrounding the explant which was added and removed after $36 \mathrm{hr}$

Series 3. The same type of network as above, without any added supporting cells. This served as a control to demonstrate that during the observation period, additional glial cells do not appear from within the supporting neuronal network. It also allowed the study of axonal characteristics in an entirely glial free environment.

Harvesting of cells and preparation for microscopy. Incubation medium was supplemented with NGF, $15 \%$ HPS, and $5 \%$ chick embryo extract. The cultures were all incubated in parallel at $37^{\circ} \mathrm{C}$ in an atmosphere of $5 \% \mathrm{CO}_{2}$. Duplicate cultures from each series were harvested by fixation at 7,14 , and

TABLE I

Number of fascicles sampled

\begin{tabular}{rccc}
\hline $\begin{array}{c}\text { Time of } \\
\text { Sampling }\end{array}$ & $\begin{array}{c}\text { Series 1: Neurites }+ \\
\text { Spinal Cord }\end{array}$ & $\begin{array}{c}\text { Series 2: Neurites + } \\
\text { Schwann Cells }\end{array}$ & $\begin{array}{c}\text { Series 3: Neurites } \\
\text { Alone }\end{array}$ \\
\hline 7 days & 6 & 6 & 0 \\
14 days & 6 & 6 & 0 \\
24 days & 6 & 6 & 4 \\
\hline
\end{tabular}
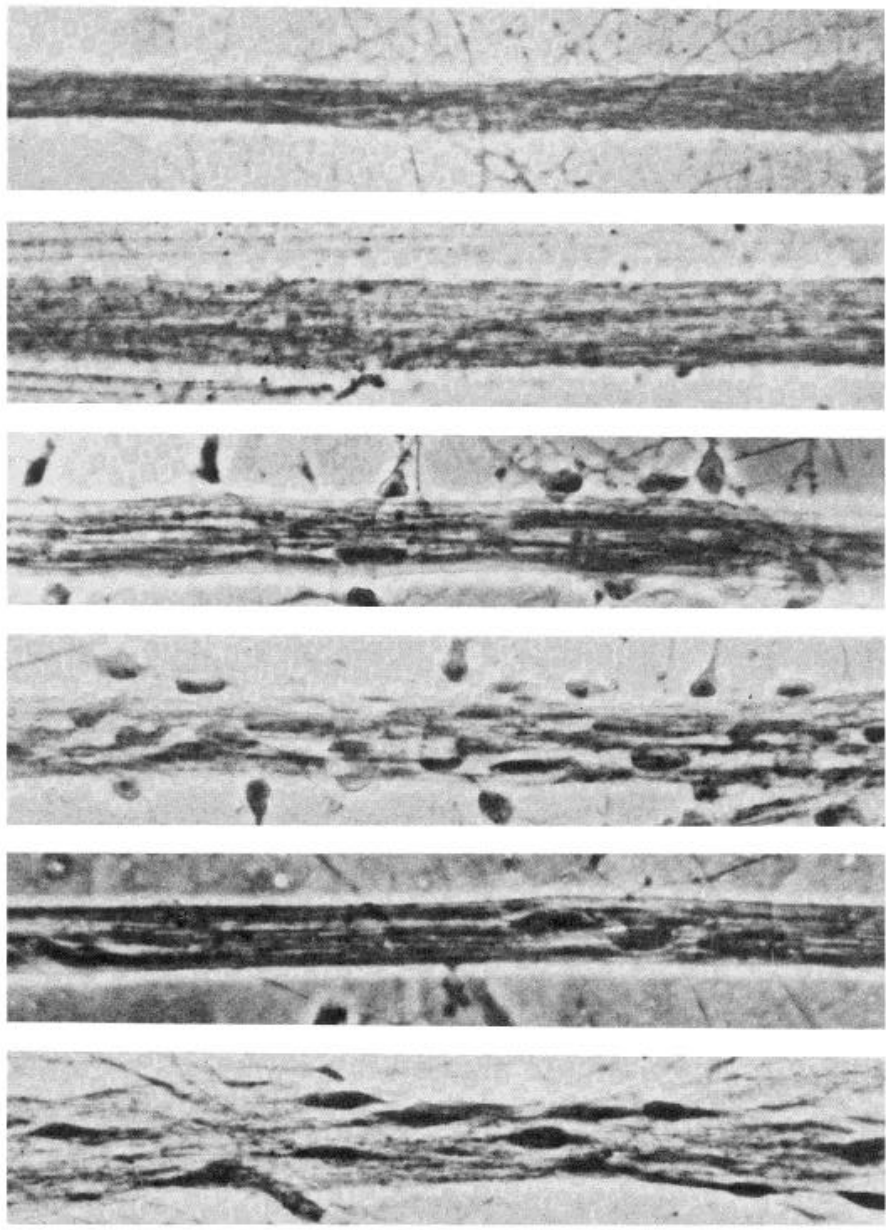

Figure 1. Fascicles of neurites sampled from dissociated dorsal root ganglion cultures. The top two frames represent fascicles of bare neurites with no supporting cells. The middle two frames represent fascicles lightly and heavily invested with glial cells derived from spinal cord. The lower two frames represent fascicles lightly and heavily invested with Schwann cells. Phase-contrast micrographs of osmicated epoxy-embedded whole-mounted cultures. Final magnification $\times 1000$.
21 days after the series above were set up. Fixation was carried out in the culture dish using $2.0 \%$ glutaraldehyde with $50 \mathrm{~mm}$ glucose in $0.025 \mathrm{M}$ phosphate buffer, with $\mathrm{pH}$ adjusted to 7.35 . The measured osmolarity of the fixative varied between 304 and $308 \mathrm{mOsm}$. After fixation for $1 \mathrm{hr}$ at room temperature, cultures were postfixed in $2 \%$ osmium tetroxide and then dehydrated and embedded in situ in an epoxy-Araldite medium. After curing, the culture dish was peeled off the block, and areas were selected for electron microscopy.

Systematic selection procedures. Since the culture dish does not provide a completely uniform physical environment and since the cells are not randomly distributed through the dish, it is essential to use a systematic sampling technique. In every case, a fascicle of neurites 100 to $200 \mu \mathrm{m}$ in diameter was selected. In dishes in which explants had been added and removed (series 1 and 2), the center of the explant position was marked, and a fascicle $2 \mathrm{~mm}$ from this point was identified. The 2-mm point was chosen in order to sample an area heavily invested with supporting cells. Two such points were sampled from each dish. A third fascicle of similar diameter was sampled from the central area of the network where no supporting cells were present. In the case of the bare network (series 3 ), points were marked where the center of an explant would have fallen, and then a fascicle $2 \mathrm{~mm}$ from this point was sampled. In every case, the fascicle sampled was one interconnecting neuron cell bodies and not one that projected radially from the edge of the dissociated neuron/neurite network. In this way, a total of 40 fascicles was sampled (Table I).

The fascicle to be sampled was marked with a circular score under the light microscope. This area was then cut out and mounted on an epoxy chuck so that thin sections might be cut at right angles to the longitudinal axis of the fascicle. Seventy-nm sections were cut, stained with lead citrate and methanolic uranyl acetate, and then examined in a Phillips 300 electron microscope. Overlapping photographs were taken of the whole fascicle at a final magnification of 22,500. This magnification was calculated using a latex line grid. From these photographs, a montage of each complete fascicle was constructed. Identification of different cell types by morphological criteria is often contenious. For the purpose of this morphometric evaluation, however, the following unequivocal identifications only were used.

1. Fascicles with no supporting cells were identified by the complete absence of nuclear staining (Fig. 1). These fascicles must be composed of neurites alone, and thus all cellular profiles were identified and counted as neurites.

2. In fascicles with supporting cells, compacted myelin may be unequivocally identified. Only neurites with a compacted myelin sheath were counted.

Diameters of neurites in the bare areas were measured using a Zeiss TGZ3 particle counter. All neurite profiles closely approximated a circle. Myelinated fiber profiles were circular, elliptical, or flattened (Fig. 2). Alignment of the plane of section to fiber axis may be assessed by examining the myelin lamellae. Thus, clear identification of major dense lines and interperiod lines can only be made when perpendicularity is closely approximated. Therefore, measurements on myelinated fibers were made in the following way with a micrometer.

1. If the profile was circular, the diameter was measured.

2. If the profile was elliptical or flattened but lamellae could be delineated around the whole fiber (Fig. 2), it was assumed that this fiber was cut at right angles, and the mean of the major and minor axis diameter was used.

3. If the profile were elliptical or flattened and lamellae could not be identified at the polar ends of the profile but could be at other points of the circumference (Fig. 2), it was assumed that this fiber had been cut obliquely, and the minor axis diameter only was chosen.

By this process, axonal diameter was calculated in a way that might slightly underestimate the true axonal diameter. Myelinated axon diameters were then allotted into $0.1-\mathrm{m}$ increments (that is, 0.0 to $0.09,0.1$ to 0.19 , ... 2.9 to $2.99 \mu \mathrm{m}$. In all cases, axon diameter was measured to the axolemma.

Diameter histograms for nonmyelinated fibers were plotted using a Hewlett-Packard programmable calculator. This was also used to calculate range of axon diameter, total number of axons counted, and median diameter of axons within one fascicle.

\section{Results}

The descriptive morphological characteristics of these cultures have been described elsewhere (Windebank et al., 1984). The principal morphometric results of this study involve two observations.

Axonal diameter in the absence of supporting cells. From each culture at different time points $(7,14$, and 24 days), from each series $(1,2$, and 3$)$, a fascicle was sampled which carried no supporting 

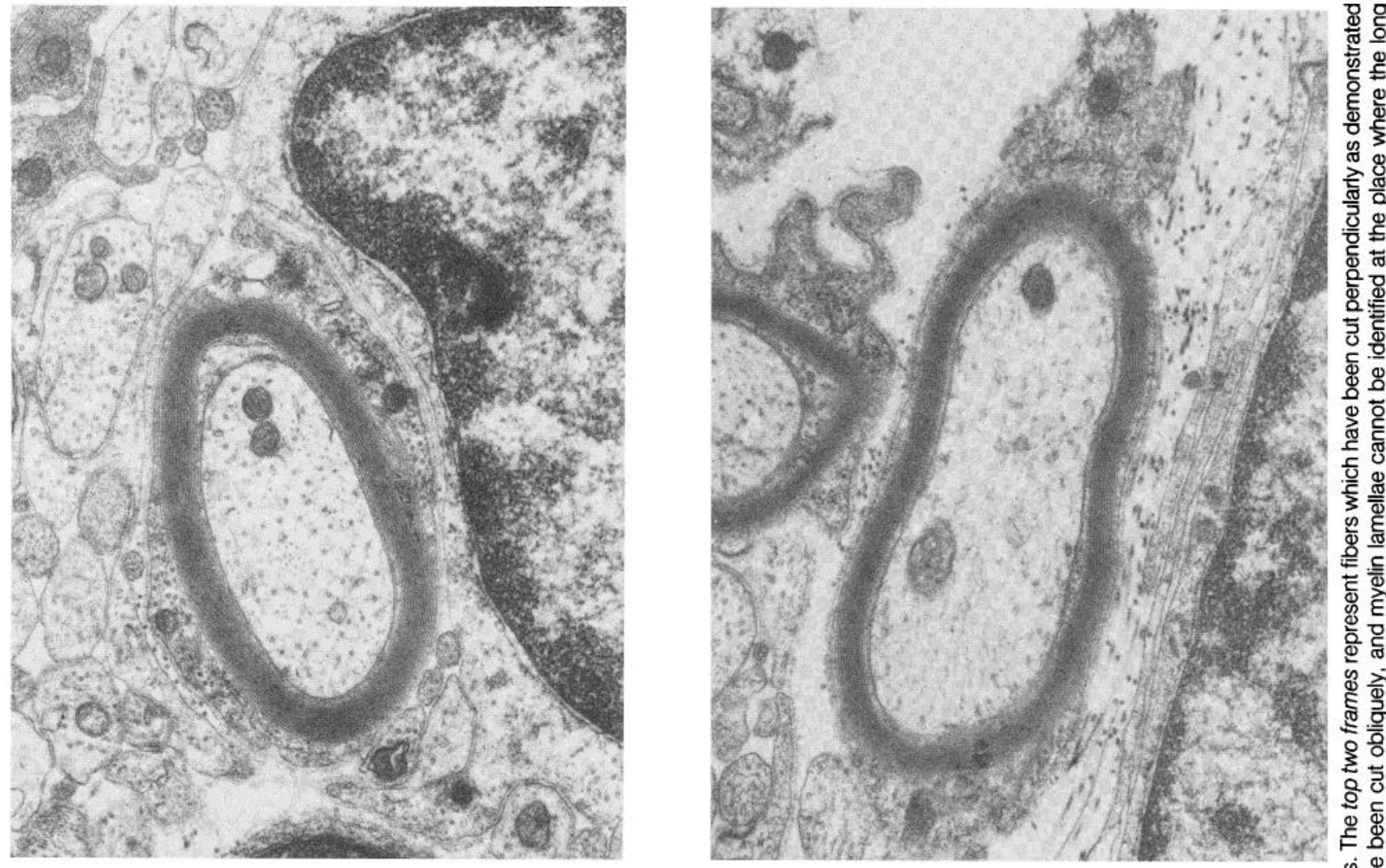

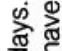

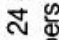
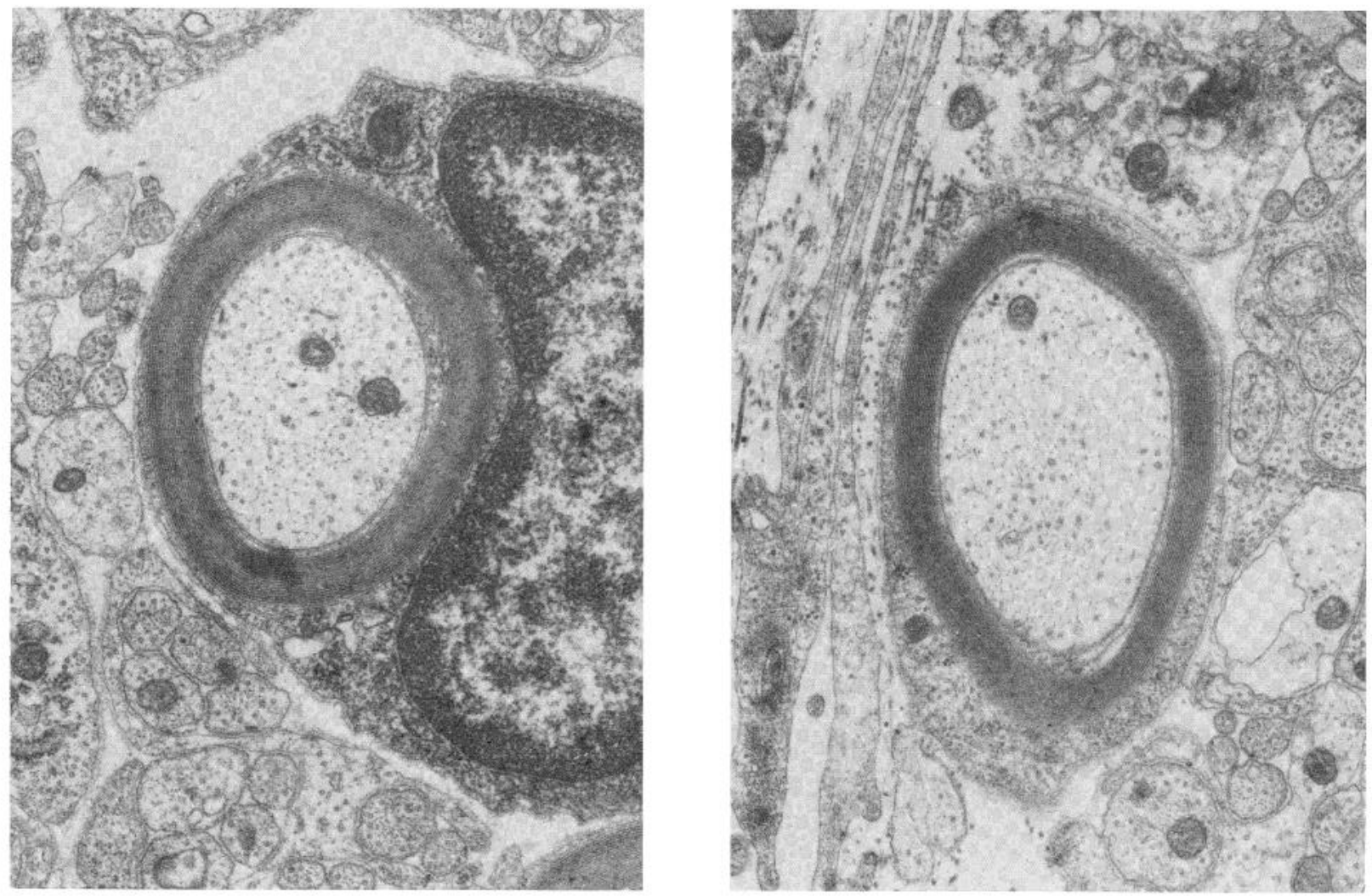

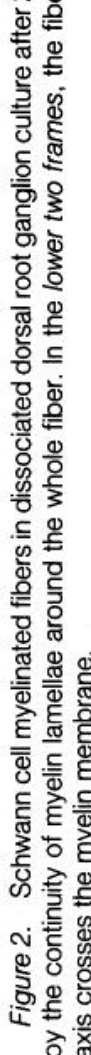


TABLE ॥

Morphometric characteristics of bare axons at different times in various cell culture systems

These fascicles contain bare neurites with no supporting cells.

\begin{tabular}{clcccc}
\hline Culture Series & $\begin{array}{c}\text { Cell Types in } \\
\text { Culture }\end{array}$ & $\begin{array}{c}\text { Time of Sampling } \\
\text { (days) }\end{array}$ & $\begin{array}{c}\text { No. of Fibers } \\
\text { Counted }\end{array}$ & $\begin{array}{c}\text { Median Diameter } \\
(\mu \mathrm{m})\end{array}$ & $\begin{array}{c}\text { Range of Diameter } \\
(\mu \mathrm{m})\end{array}$ \\
\hline 2 & DRG ${ }^{a}$ and SC & 7 & 899 & $0.21 \pm 0.20^{\circ}$ & $0.05-1.20$ \\
2 & DRG and SC & 7 & 733 & $0.24 \pm 0.20$ & $0.05-1.25$ \\
1 & DRG and cord & 7 & 781 & $0.29 \pm 0.19$ & $0.05-1.25$ \\
1 & DRG and cord & 7 & 981 & $0.25 \pm 0.23$ & $0.05-1.20$ \\
2 & DRG and SC & 14 & 637 & $0.22 \pm 0.13$ & $0.05-0.90$ \\
1 & DRG and cord & 14 & 981 & $0.27 \pm 0.16$ & $0.05-1.20$ \\
1 & DRG and cord & 14 & 918 & $0.22 \pm 0.11$ & $0.05-1.10$ \\
2 & DRG and SC & 24 & 707 & $0.27 \pm 0.18$ & $0.05-1.20$ \\
2 & DRG and SC & 24 & 491 & $0.24 \pm 0.15$ & $0.05-1.00$ \\
1 & DRG and cord & 24 & 1067 & $0.27 \pm 0.17$ & $0.05-1.10$ \\
1 & DRG and cord & 24 & 827 & $0.20 \pm 0.13$ & $0.05-1.15$ \\
3 & DRG alone & 24 & 870 & $0.25 \pm 0.17$ & $0.05-1.10$ \\
3 & DRG alone & 24 & 1427 & $0.23 \pm 0.15$ & $0.05-1.20$ \\
3 & DRG alone & 24 & 1184 & $0.23 \pm 0.14$ & $0.05-1.10$ \\
\hline
\end{tabular}

${ }^{a} \mathrm{DRG}$, dorsal root ganglion; SC, Schwann cells.

${ }^{\mathrm{D}}$ Mean $\pm \mathrm{SD}$.

cells. The number of fibers counted and the median diameter, standard deviation, and range of fiber diameters is detailed in Table II. These findings demonstrate that reproducible morphometric data can be derived from tissue culture samples. From these systematically sampled fascicles, there is little variability from dish to dish in terms of median fiber diameter or range of diameter present. There is no consistent difference in these diameter characteristics between dishes containing Schwann cells in other parts of the culture (series 2), dishes containing glial cells derived from spinal cord (series 1), or dishes in which no supporting cells have been added (series 3 ). If the results are summed for the various time points (Fig. 3), it can be seen that, from day 7 to 24 , a stable population of unmyelinated fibers exists in this culture situation.

Axonal diameter of myelinated fibers. Ensheathment of axons by supporting cells was present in the cultures at 7 and 14 days. However, significant numbers of fibers with compacted myelin were not found at the site of sampling until 24 days after setting up the combined cultures. Therefore, measurements of myelinated fibers are made only on the 24-day cultures, and the results are summarized in Figure 4. At this time point, the cultures of dorsal root ganglion neurons to which no supporting cells had becn added (series 3) remained free of glial or Schwann cells on the neurite network. The following conclusions may be made.

(a) Myelinated axons have a greater diameter than axons without supporting cells in this culture system. The mean of median diameter of both Schwann cell myelinated fibers $(1.67 \mu \mathrm{m})$ and spinal cordderived glial cell myelinated fibers $(1.13 \mu \mathrm{m})$ are greater than bare fibers at a highly significant level $(p<0.001)$. The range of fiber diameters is also completely different. Bare axons were never seen to achieve a diameter greater than $1.25 \mu \mathrm{m}$. However, $90.1 \%$ of myelinated fibers in the Schwann cell cultures and $44.8 \%$ of myelinated fibers in the spinal cord derived cultures had diameters greater than $1.25 \mu \mathrm{m}$.

(b) The mean of median diameter of myelinated fibers in the spinal cord (series 1) cultures was significantly less than those in the Schwann cell (series 2$)$ cultures $(p<0.001)$. This may in part represent a difference in rate of maturation of the cultures. This was assessed by counting the number of compacted myelin lamellae around each fiber. For the Schwann cell-derived cultures, the mean number of lamellae per axon was $11.3(\mathrm{SD}=3.0)$, whereas the spinal cord glial myelinated axons carried $8.4(\mathrm{SD}=2.8$ ) lamellae. Although the Schwann cells showed more maturity by this criterion, the difference is not statistically significant $(p>0.1)$.

\section{Discussion}

The importance of quantifying data derived from cell cultures has been stressed particularly by Varon et al. (1982).

The methods used in this study demonstrate that techniques which have been applied to the peripheral nervous system of the intact organism (Dyck et al., 1984b) may bc uscd in ccll culturcs from the nervous system. The culture dish, however, offers a different situation because of potentially greater variability in organization. Variables include source of cells, identity of developmental stage of the cells, preparation techniques, distribution of cells in the dish, substratum, and supporting medium or growth factors. In this study, all of the cells were derived from the embryos of a single mother and processed at one time to produce the neuronal network on a collagen substrate. All of the cultures were incubated in the same growth medium for the same time period. The only variable was the types of additional cells (series 1 to 3 ) added at the onset of the observation period. Careful consideration was also given to the method of sampling, and a systematic rather than random procedure was used. The consistency of the results obtained in this way is illustrated by the data in Table 2 .

The major observation is that myelinated axons have a larger diameter than bare axons. The expression of this greater axonal diameter depends on the establishment of a relationship with a myelinating cell. In fascicles in which supporting cells were not present, axons never exceeded $1.25 \mu \mathrm{m}$ in diameter. This observation was true both when fascicles without supporting cells were sampled from culture dishes which contained neurons alone (series 3) and when bare fascicles were taken from dishes which did contain Schwann cells (series 2) or oligodendroglia (series 1) elsewhere in the dish. This demonstrates that the factor allowing attainment of greater diameter is not soluble or secreted into the medium but rather depends upon cell to cell contact. This study specifically addresses the question of myelination as a permissive factor in the expression of axonal diameter; il does nol answer whether ensheathment of an axon by Schwann cells which does not result in myelination will produce the same result. The two categories of axons used in this study were unequivocally identifiable. That is bare axons in fascicles containing no glial cells or myelinated axons,

The implication of these findings is that, in cell culture, axons reach a certain size but then cannot grow beyond that size unless they are myelinated. This is a reversal of the usual concept that the axonal size determines whether a fiber will be myelinated. It implies that axonal diameter is determined not only by information in the neuronal perikaryon but also by specific cellular interactions with 

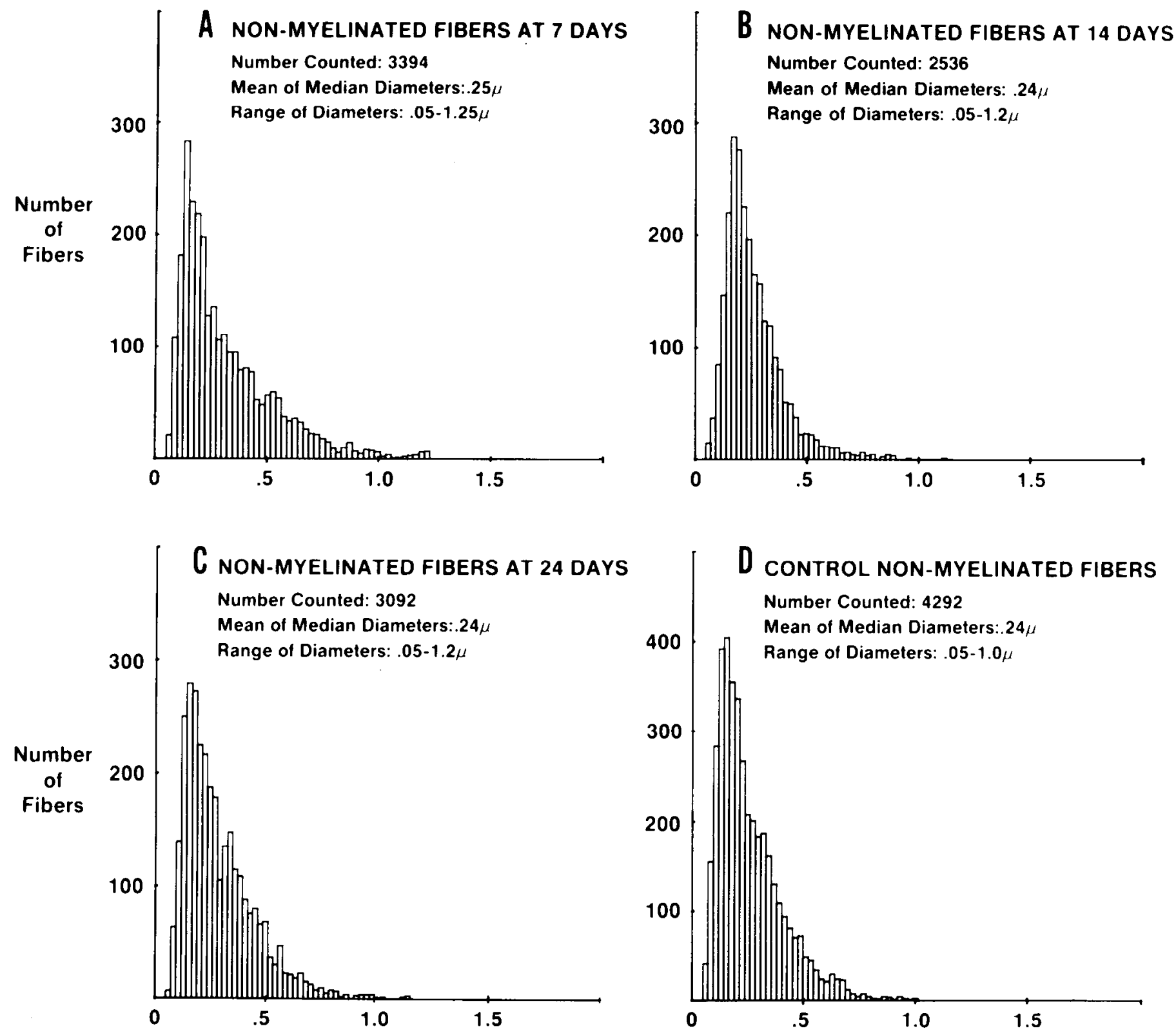

Fiber Diameter in Microns

Figure 3. Diameter histograms for bare dorsal root ganglion neurites in tissue cultures containing glial cells $(A, B$, and $C$ ) or no supporting cells ( $D$ ) at various times after setting up the cultures. The histograms demonstrate that a stable-sized population of neurites is present during the observation period.

glial cells. There is no evidence to support an alternative explanation that a population of larger fibers grow out but cannot survive in the absence of myelination.

The relationship of axonal diameter to myelination was first clearly described by Duncan (1934). His morphometric observations in adult cow, cat, and rat peripheral nerves suggested that there was a critical axonal diameter for myelination. Axons less than $1.0 \mu \mathrm{m}$ in diameter were always unmyelinated, while those greater than 2.0 $\mu \mathrm{m}$ were myelinated. The physiological basis for the advantage of this was set out by Rushton (1951), who demonstrated that $1 \mu \mathrm{m}$ is the critical diameter above which myelination improves conduction velocity more than diameter increase. The corollary is that myelinated axons less than $1 \mu \mathrm{m}$ in diameter would conduct more slowly than an unmyelinated axon of similar diameter. It has been assumed that regulation of diameter was a property of the axon or the neuron and that large axons are produced by large neurons in the DRG and small axons by small neurons. It is of note that the differentiation of neurons into a large and small population occurs in the rat between
E13 and postnatal day 14 (Lawson et al., 1976). Thus neuronal differentiation, by morphological criteria, occurs in parallel to the maximum period of peripheral myelination. There is no evidence, however, that Schwann cells are differentiated into subpopulations that would allow them to determine the characteristics of an axon. Present knowledge suggests that Schwann cells are not differentiated even in the adult. Schwann cells normally involved in ensheathing nonmyelinated fibers may myelinate if the correct axonal signal is delivered (Aguayo et al., 1976). Similarly, in both tissue culture (Salzer et al., 1980b) and animal models of the biochemical events in myelinogenesis (Poduslo, 1984), there is good evidence that the axon is of primary importance in the stimulation and regulation of myelin production. If the axon is made to atrophy, then secondary demyelination occurs (Dyck et al., 1984a).

The possibility of local regulation of axonal diameter has been ráised by several studies. Aguayo et al. (1979) have studied nerve grafts between normal and trembler mice. Their findings demonstrated that when normal axons pass through a graft and are 

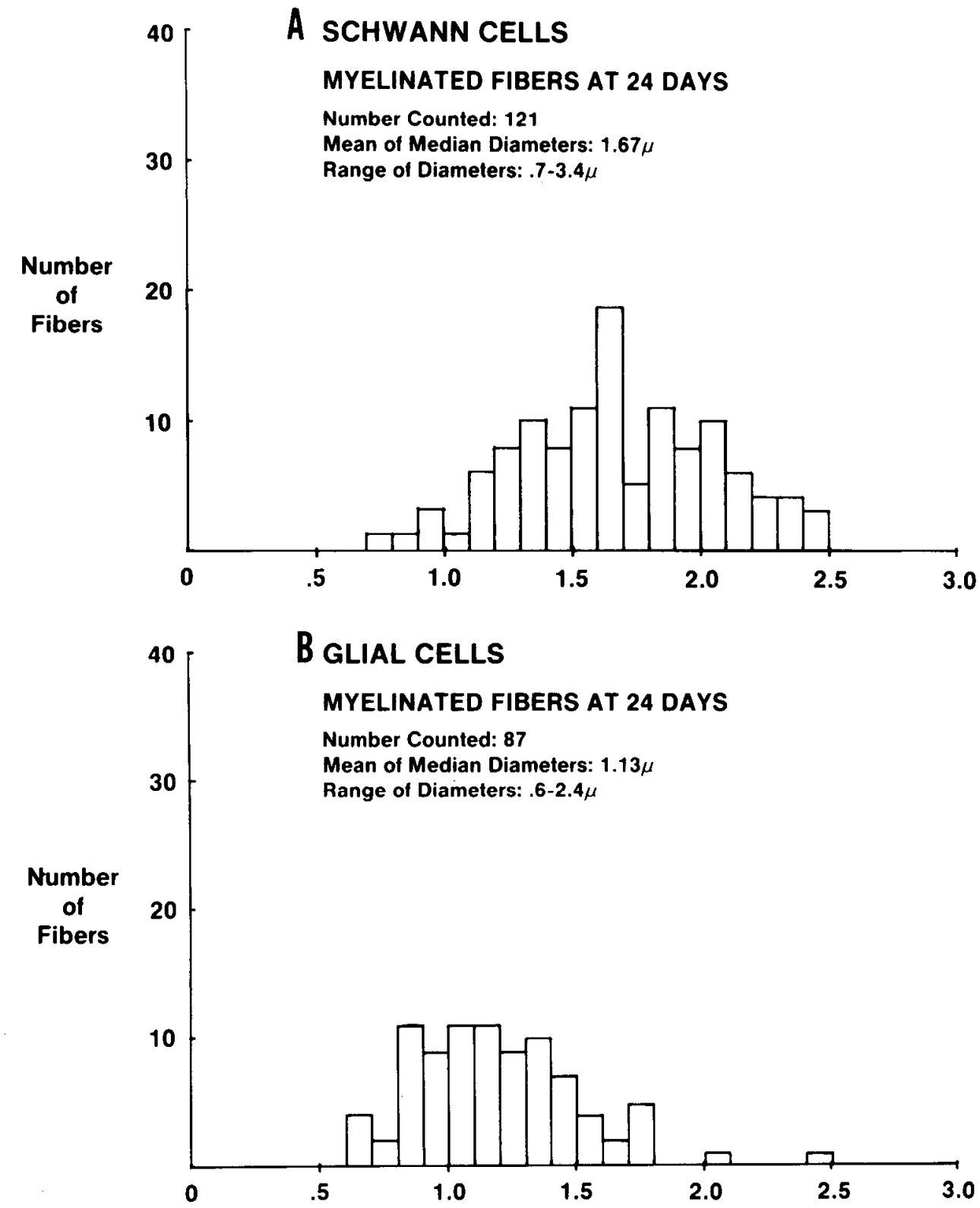

Figure 4. Diameter of myelinated dorsal root ganglion axons after 24 days in culture. The axons had been myelinated either by Schwann cells derived from the DRG $(A)$ or oligodendrocytes derived from the spinal cord $(B)$.

Fiber Diameter in Microns

hypomyelinated by trembler Schwann cells, axonal caliber is reduced, but the caliber returns to normal when the axons re-enter the distal nerve stump and are normally myelinated. A similar relationship has been suggested in experimental allergic encephelomyelitis (Raine et al., 1969) and in chronic inflammratory demyelinating polyradiculoneuropathy in humans (Prineas and McLeod, 1976). Both groups of workers note that alteration of the axon appears to occur locally in regions of segmental demyelination. Prineas and McCleod (1976) noted that the density of neurofilaments and neurotubules was increased and the axolemma was wrinkled in such areas. This led to their hypothesis that loss of myelination might lead to a local loss of fluid from the axon with subsequent shrinkage. That such osmotic changes might lead to axonal shrinkage has been well demonstrated (Dyck et al., 1980, 1981), but the significance of this for the developmental situation is unclear.

During development, Fraher (1978) has studied ventral root fibers in the region where they pass from the spinal cord into the root. Using very careful morphometric techniques, he has demonstrated that the same axon has a smaller diameter in the cord. The average ratio of peripheral to central axonal caliber was 1.3 , implying some form of local regulation of axonal size. It was also of note that in the present study, the mean of median diameter of axons myelinated by oligodendrocytes was significantly less than those myelinated by Schwann cells. These various observations may be integrated into a scheme with the following characteristics.

1. The primary determinant of axon caliber rests in the perikaryon of the neuron.

2. The neuron supplies the stimulus to the Schwann cell by way of axolemmal (or other) determinants to function as either a myelinating or an ensheathing, nonmyelinating Schwann cell.

3. The maintenance of myelination depends on continued axon Schwann cell contact and continued maintenance of a specific axonal caliber.

4. The absence of Schwann cell or neuroglial support will prevent an axon from achieving or expressing its full predetermined caliber. This will occur either in development where myelinating elements are malfunctioning or in disease where demyelination occurs.

This implies a dynamic, mutually interdependent relationship between axons and their supporting cells. It is of note that, in this culture system, the neuronal perikaryon never reaches the size of 
cells in the adult animal, even in prolonged culture (Bunge et al., 1967). Similarly, myelinated fibers do not exceed $3.5 \mu \mathrm{m}$ in diameter, whereas large sensory fibers may have diameters of 12 to $14 \mu \mathrm{m}$ in the adult rat. Whether this is due to absence of specific media factors, different substratum, or lack of the appropriate target or sensory receptor cell is not known. The dissection of this interdependence can best be studied in tissue culture with defined populations of cells.

\section{References}

Aguayo, R. A., J. Epps, L. Charron, and G. Bray (1976) Multipotentiality of Schwann cells in cross-anastomosed and grafted myelinated and unmyelinated nerves: Quantitative microscopy and radioautography. Brain Res. 104: $1-20$

Aguayo, A. J., G. Bray, and S. Perkins (1979) Axon-Schwann cell relationships in neuropathies of mutant mice. Ann. N. Y. Acad. Sci. 317: 512-531.

Bradel, E. J., and F. P. Prince (1983) Cultured neonatal rat oligodendrocytes elaborate myelin membrane in the absence of neurons. J. Neurosci. Res. 9: 381-392.

Bunge, M. B., R. P. Bunge, E. R. Peterson, and M. R. Murray (1967) A light and electron microscope study of long-term organized cultures of rat dorsal root ganglia. J. Cell Biol. 32: 439-466.

DeVries, G. H., J. L. Salzer, and R. P. Bunge (1982) Axolemma-enriched fractions isolated from PNS and CNS are mitogenic for cultured Schwann cells. Dev. Brain Res. 3: 295-299.

Duncan, D. (1934) A relation between axone diameter and myelination determined by measurement of myelinated spinal root fibers. J. Comp. Neurol. 60: 437-471.

Dyck, P. J., P. A. Low, M. F. Sparks, L. A. Hexum, and J. L. Karnes (1980) Effect of serum hyperosmolality on morphometry of healthy human sural nerve. J. Neuropathol. Exp. Neurol. 39: 285-295.

Dyck, P. J., E. H. Lambert, A. J. Windebank, A. C. Lais, M. F. Sparks, J. Karnes, W. R. Sherman, L. M. Hallcher, P. A. Low, and F. J. Service (1981) Acute hyperosmolar hyperglycemia causes axonal shrinkage and reduced nerve conduction velocity. Exp. Neurol. 71: 507-514.

Dyck, P. J., H. Nukada, A. C. Lais, and J. L. Karnes (1984a) Permanent axotomy: A model of chronic neuronal degeneration preceded by axonal atrophy, myelin remodeling and degeneration. In Peripheral Neuropathy, Ed. 2, P. J. Dyck, P. K. Thomas, E. H. Lambert, and R. Bunge, eds., pp. $666-690$, W. B. Saunders, Philadelphia
Dyck, P. J., J. Karnes, A. Lais, E. O. Lofgren, and J. C. Stevens (1984b) Pathologic alterations of the peripheral nervous system of humans. In Peripheral Neuropathy, Ed. 2, P. J. Dyck, P. K. Thomas, E. H. Lambert, and R. Bunge, eds., pp. 760-870, W. B. Saunders, Philadelphia.

Ernyei, S., and M. R. Young (1966) Pulsatile and myelin-forming activities of Schwann cells in vitro. J. Physiol. (Lond.) 183: 469-480.

Fraher, J. P. (1978) Quantitative studies on the maturation of central and peripheral parts of individual ventral motoneuron axons. I. Myelin sheath and axon calibre. J. Anat. 126: 509-533.

Lawson, S. N., K. W. T. Caddy, and T. J. Biscoe (1974) Development of rat dorsal root ganglion neurones: Studies of cell birthdays and changes in mean cell diameter. Cell Tissue Res. 153: 399-413.

Poduslo, J. F. (1984) Regulation of myelination: Biosynthesis of the major myelin glycoprotein by Schwann cells in the presence and absence of myelin assembly. J. Neurochem. 42: 493-503.

Poduslo, J. F., C. T. Berg, and P. J. Dyck (1984) Schwann cell expression of a major myelin glycoprotein in the absence of myelin assembly. Proc. Natl. Acad. Sci. U. S. A. 81: 1864-1866.

Prineas, J. W., and J. G. McLeod (1976) Chronic relapsing polyneuritis. J. Neurol. Sci. 27: 427-458.

Raine, C. S., H. Wisniewski, and J. Prineas (1969) An ultrastructural study of experimental demyelination and remyelination. Lab. Invest. 21: 316-327.

Rushton, W. A. H. (1951) A theory of the effects of fibre size in medullated nerve. J. Physiol. (Lond.) 115: 101-122.

Salzer, J. L., A. K. Williams, L. Glaser, and R. P. Bunge (1980a) Studies of Schwann cell proliferation. II. Characterization of the stimulation and specificity of the response to a neurite membrane fraction. J. Cell Biol. 84: 753-766.

Saizer, J. L., R. O. Bunge, and L. Glaser (1980b) Studies of Schwann cell proliferation. III. Evidence for the surface localization of the neurite mitogen. J. Cell Biol. 84: 767-778.

Varon, S., and M. Manthorpe (1982) Schwann cells: An in vitro perspective. Adv. Cell. Neurobiol. 3: 35-95.

Windebank, A. J., P. Wood, and R. P. Bunge. (1984) Differentiated Features of Central and Peripheral Myelination Are Expressed in Culture. J. Neurocytol., in press.

Wood, P. M. (1976) Separation of functional Schwann cells and neurons from normal peripheral nerve tissue. Brain Res. 115: 361-375.

Wood, P., E. Okada, and R. Bunge (1980) The use of networks of dissociated rat dorsal root ganglion neurons to induce myelination by oligodendrocytes in culture. Brain Res. 196: 247-252. 